\title{
Effect of Silicon on AHSS As-Cast Microstructure Development and Properties
}

\author{
Rafael Coura GIACOMIN* and Bryan A. WEBLER \\ Carnegie Mellon University, 5000 Forbes Ave., Pittsburgh - PA, 15213 USA. \\ (Received on September 5, 2018; accepted on December 12, 2018; J-STAGE Advance published date: \\ February 2, 2019)
}

\begin{abstract}
This work linked properties and performance in as-cast condition for 3rd generation advanced high strength steel (AHSS) by examining the effects of chemical composition and microstructure on mechanical properties. Elevated levels of carbon, manganese, and silicon in new AHSS grades lead to a complex evolution of microstructure during solidification that can lead to castability problems. Three lab cast ingots with 0.2 wt \% C, 3 wt \% Mn, and 0.5, 1.5, and 3 wt \% Si were characterized by their microstructure and mechanical properties. Light optical microscopy (LOM) and Scanning Electron Microscopy (SEM) confirmed that the microstructure of steels was mostly granular bainite, with some proeutectoid ferrite allotriomorphs at $3 \mathrm{wt} \% \mathrm{Si}$. Tensile testing showed Si increased strength and that ductility of all samples was low. Higher silicon levels were found to promote formation of proeutectoid ferrite allotriomorphs and changed the cracking propagation behavior. Some comparisons between the observed microstructures and those expected in continuously cast slabs were also discussed.
\end{abstract}

KEY WORDS: AHSS; microstructure; cracking; ferrite allotriomorphs; DICTRA.

\section{Introduction}

Development of steels for automotive applications has been primarily driven by the need for improved crashworthiness and fuel economy. ${ }^{1)}$ The Advanced High Strength Steel (AHSS) grades enable achieving both of these performance goals in a cost-effective way. ${ }^{2)}$ The AHSS grades are typically categorized by their mechanical properties, most often combinations of tensile strength vs. elongation. The first generation of AHSS were the dual phase (DP), complex phase (CP) and transformation induced plasticity (TRIP). These steels employed microstructures of ferrite, bainite, martensite, and retained austenite to achieve higher strength and ductility than, e.g. the high strength low alloy (HSLA) grades. The second generation of AHSS grades, Twining Induced Plasticity (TWIP), offered excellent property combinations but were very highly alloyed and production is limited in the existing steel production infrastructure. The 3rd Generation AHSS are under development to occupy an intermediate space, where good combinations of strength and ductility can be achieved with lower alloying additions.

Heat treatments of 3rd Gen AHSS are designed to produce carbon-enriched, metastable, retained austenite, which is considered beneficial because transformation plasticity during deformation contributes to work hardening, formability, and fracture toughness. ${ }^{3)}$ To achieve such, the chemical composition of this type of steels is usually $0.12-0.20 \% \mathrm{C}$, $1.8-5.0 \% \mathrm{Mn}, 0.2-3.0 \% \mathrm{Si}$ and $0.04-3.00 \% \mathrm{Al}^{1,4-6)}$ (usu-

\footnotetext{
* Corresponding author: E-mail: rgiacomi@andrew.cmu.edu DOI: https://doi.org/10.2355/isijinternational.ISIJINT-2018-598
}

ally $\mathrm{Si}$ and $\mathrm{Al}$ replace each other, since their effect in steel properties are similar). There are a fairly wide range of alloying possibilities for grades that are still very new to the steelmaking industry. ${ }^{3-7)}$ Carbon is added to steel with objective of increasing hardenability and manganese also promotes hardenability in heat treatable steels by retarding transformation of austenite. ${ }^{8)}$ Both manganese and silicon contribute to solid-solution strengthening of ferrite. ${ }^{9)}$ Silicon and aluminum are key components in these grades and often replace each other, since both inhibit cementite formation and allow more carbon to be partitioned and stabilize austenite. $^{9-11)}$

There have been numerous studies on the solid-state thermomechanical processing of these steels, ${ }^{1-7)}$ but there are far fewer studies dealing with melting, refining, and casting of these grades. ${ }^{12)}$ As interest in 3rd Generation AHSS increases, characterization of microstructure and properties during processing could be used to diagnose potential issues during large-scale production.

Flat steels for automotive applications, like these 3rd Generation AHSS, are produced by continuous casting of thick slabs, approximately $250 \mathrm{~mm}$ thick. During continuous casting, liquid steel is poured into a water-cooled copper mold, where it cools at a rate of approximately $80^{\circ} \mathrm{C} / \mathrm{s}^{13}$ ) and the formed strand is subsequently cooled in the spray zone at cooling rates of approximately $0.5^{\circ} \mathrm{C} / \mathrm{s} .{ }^{14)}$ After unbending and cutting when temperatures are approximately $900^{\circ} \mathrm{C}$, the slabs are usually air cooled in stacks. Those stacks may or may not be covered by an insulated box. In some facilities slabs are directly charged from the caster into reheat furnaces before they cool below some critical 
temperature. This practice, known as direct hot charging, can mitigate defects but it limits operational flexibility. Common defects in continuously cast slabs are transverse cracking (a hot ductility issue), centerline segregation (a macrosegregation phenomenon), oscillation marks (caused by oscillating action of the mold), hydrogen induced cracking (a problem that arises due to high concentration of hydrogen in the melt), and longitudinal cracking (usually a thermo-mechanical defect). ${ }^{15-18)}$ There has been less focus on continuously cast microstructure because cast slabs are a semi-finished product and there are major changes to microstructure that occur during downstream processing. One example of as-cast slab microstructure concerns is in high manganese grades, when microsegregation during continuous casting leads to microstructural banding ${ }^{9)}$ after hot rolling.

Various microstructural phases and constituents can form due to solid-state transformations in steel. The products of these transformations depend on the transformation temperature, cooling rates, and steel composition. ${ }^{9,10,19,20)}$ The presence of carbon and manganese strongly affect these transformations. In a low carbon steel (less than 0.2 $\mathrm{wt} \%$ ), the as-cast microstructure would be expected to be a mixture of ferrite and pearlite because of the slow cooling rates after continuous casting. ${ }^{9,21)}$ However, the high levels of alloying elements in 3rd Gen AHSS grades could result in the appearance of other constituents. This study focused on the effect of silicon levels on as-cast microstructure and properties in a steel with $0.2 \mathrm{wt} \% \mathrm{C}$ and $3 \mathrm{wt} \% \mathrm{Mn}$. In this study laboratory ingots with controlled compositions were used to examine trends in as-cast microstructures and mechanical properties.

\section{Materials and Experimental Methods}

The materials investigated in the present work include three, laboratory cast, steel ingots of compositions shown in Table 1.

The ingot cross-section was rectangular, $76 \mathrm{~mm}$ by 190 $\mathrm{mm}$, and length was $264 \mathrm{~mm}$. Samples were induction-melted in an argon atmosphere and poured into a cast-iron mold. The three ingots were produced from the same parent heat. Electrolytic iron was the base material and then additions were made to create the $0.5 \mathrm{wt} \%$ silicon ingot (with other elements as shown in Table 1$)$. This ingot $(0.5 \mathrm{Si})$ was poured at $1593^{\circ} \mathrm{C}$ and afterward a silicon addition was made to produce the $1.5 \mathrm{wt} \% \mathrm{Si}$ ingot. Finally, a second $\mathrm{Si}$ addition was made, and the $3.0 \mathrm{wt} \%$ silicon sample was poured. Each mold contained electrolytic iron chips at the bottom and each mold was covered with a hot top after pouring was complete.
Samples were taken for metallographic preparation, hardness testing, and tensile testing. Sample location and dimensions are shown in Fig. 1.

Steel microstructures were examined by light optical microscopy (LOM) and scanning electron microscopy (SEM). Specimens were mounted in bakelite, ground and polished to a $1 \mu \mathrm{m}$ diamond finish, and etched in nital $(2 \%$ nitric acid in ethanol) to reveal the final microstructure. All LOM images were made with a Zeiss Axio Imager M2 $\mathrm{m}$ upright optical microscope. SEM was performed on a Phillips/FEI XL-30 operated at $10 \mathrm{kV}$ in secondary electron (SE) imaging mode. When present, allotriomorphic ferrite thickness was measured from LOM images using ImageJ software. Rockwell C hardness tests were performed in the lab cast ingots using an Instron Wilson Rockwell 2000 tester with $150 \mathrm{~kg}$ applied load.

Tensile testing on the $0.5 \mathrm{Si}$ and $1.5 \mathrm{Si}$ material was performed on a $100 \mathrm{kN}$ capacity MTS 880 servo-hydraulic load frame. Tests were conducted with a displacement rate of $0.0254 \mathrm{~mm} / \mathrm{s}$, which corresponded to an engineering strain rate of $5 \times 10^{-4} \mathrm{~s}^{-1}$ and specimens were instrumented with a $25.4 \mathrm{~mm}$ gage length extensometer. Tensile tests on the 3.0Si samples were conducted on a $245 \mathrm{kN}$ capacity MTS 312 load frame with the same displacement rate of 0.0254 $\mathrm{mm} / \mathrm{s}$ (strain rate of $5 \times 10^{-4} \mathrm{~s}^{-1}$ ) and specimens were instrumented with a $50.8 \mathrm{~mm}$ gage length extensometer. All specimens were pulled to fracture. The data was analyzed to determine the $0.2 \%$ offset yield strength (YS), the ultimate tensile strength (UTS). Percent elongation (\%EL) was determined by measuring gauge length before and after failure using a caliper and the percent reduction in area (\%RA) was determined by measuring gauge diameter before and after failure using a micrometer.

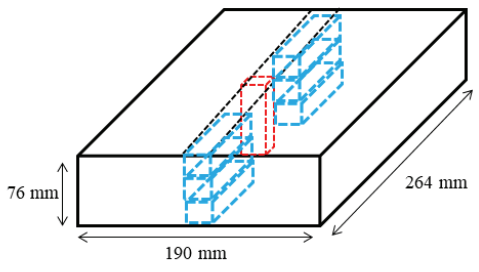

(a)

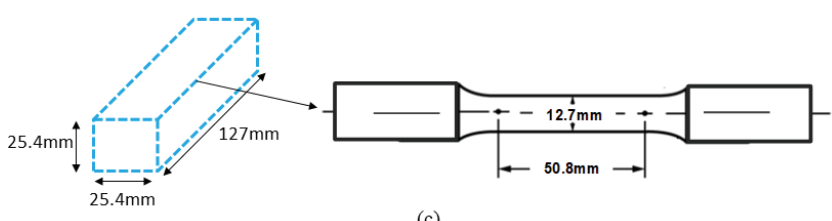

(c)
Fig. 1. Sampling scheme of lab cast ingot (a) position and (b) microstructure and (c) tensile test specimens cut. (Online version in color.)

Table 1. Chemical composition of ingots (wt $\%)$.

\begin{tabular}{|c|c|c|c|c|c|c|c|c|c|c|c|c|c|c|c|c|}
\hline \multicolumn{4}{|c|}{ Major alloying elements } & \multicolumn{13}{|c|}{ Other elements } \\
\hline Steel & $\mathrm{C}$ & $\mathrm{Mn}$ & $\mathrm{Si}$ & $\mathrm{Al}$ & $\mathrm{P}$ & S & $\mathrm{N}$ & $\mathrm{Cu}$ & $\mathrm{Ni}$ & $\mathrm{Cr}$ & Mo & V & $\mathrm{Ti}$ & $\mathrm{Nb}$ & B & $\mathrm{Sn}$ \\
\hline $0.5 \mathrm{Si}$ & 0.19 & 3.03 & 0.51 & 0.038 & 0.015 & 0.003 & 0.0064 & 0.021 & 0.021 & 0.05 & 0.001 & 0.004 & 0.001 & 0.001 & 0.0003 & 0.003 \\
\hline $1.5 \mathrm{Si}$ & 0.19 & 3.03 & 1.58 & 0.039 & 0.016 & 0.003 & 0.0063 & 0.021 & 0.021 & 0.05 & 0.001 & 0.004 & 0.001 & 0.001 & 0.0003 & 0.007 \\
\hline 3.0Si & 0.19 & 2.95 & 3.26 & 0.037 & 0.015 & 0.003 & 0.0058 & 0.020 & 0.020 & 0.05 & 0.000 & 0.004 & 0.001 & 0.001 & 0.0003 & 0.009 \\
\hline
\end{tabular}


Two simulation approaches were employed to interpret results and develop connections between the lab-cast ingots and continuously cast slabs. A model was developed using QuikCAST package (3D simulation of a quarter symmetry of the pieces with conditions shown in Table 2) as to compare temperature profile of air cooled $190 \times 76 \times 264 \mathrm{~mm}$ ingots with continuously cast $1270 \times 230 \times 9144 \mathrm{~mm}$ slabs. The conditions applied for continuously cast slabs were simplifications of strand/slab surface temperature found in the literature. ${ }^{22,23)}$

A thermodynamic and kinetic simulation of ferrite growth was performed with DICTRA and Thermo-Calc software using MOBFE4 and TCFE9 databases. ${ }^{24)}$ The applied boundary conditions were summarized in Fig. 2. A one-dimensional simulation was carried on a $1 \mathrm{~mm}$ piece of steel with chemistries shown in Table 1 - only iron, carbon, manganese and silicon were used in the simulation. Ferrite

Table 2. Cooling simulation conditions.

\begin{tabular}{ccc}
\hline Simulation & Time $(\mathrm{s})$ & Boundary Condition \\
\hline \multirow{3}{*}{ Slab } & 0 & Surface $\mathrm{T}=1532^{\circ} \mathrm{C}$ \\
& 2.5 & Surface $\mathrm{T}=950^{\circ} \mathrm{C}$ \\
& 35 & Surface $\mathrm{T}=800^{\circ} \mathrm{C}$ \\
Ingot & $>0$ & $\begin{array}{c}\text { Natural convection }+ \text { radiation }(\varepsilon=0.3) \text { cooling } \\
\text { Cast iron mold at sides and bottom + air and } \\
\text { radiation cooling on top surface }\end{array}$ \\
\hline
\end{tabular}

was set as an inactive phase on the left side for time $=0$ $\mathrm{s}$ and simulation was carried on with temperature varying from $1200^{\circ} \mathrm{C}$ to $\mathrm{A}_{1}\left(674,687\right.$ and $713^{\circ} \mathrm{C}$ for $0.5 \mathrm{Si}, 1.5 \mathrm{Si}$ and 3.0Si respectively) at two cooling rates: (1) $40^{\circ} \mathrm{C} / \mathrm{min}$ to represent the average cooling rate of the ingots and (2) $6^{\circ} \mathrm{C} / \mathrm{min}$ representing the average cooling rate of a continuously cast slab (based on QuikCAST simulations described above). Expected ferrite thickness was analyzed for the different conditions.

\section{Results}

Figure 3 shows the LOM images of $+1 / 2$ Thickness (i.e. ingot surface), $+1 / 4$ Thickness and center portions of all steels. Nital etching revealed ferrite grain boundaries and microstructure constituents. ${ }^{25)}$ Figure 4 shows the SEM images of $+1 / 2$ Thickness, $+1 / 4$ Thickness and center portions of all steels along with major constituents observed in the analysis, where:

- $\mathrm{GB}=$ granular bainite

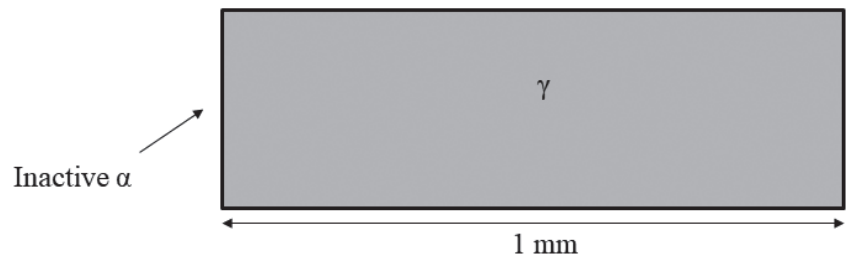

Fig. 2. Boundary conditions for DICTRA simulation.

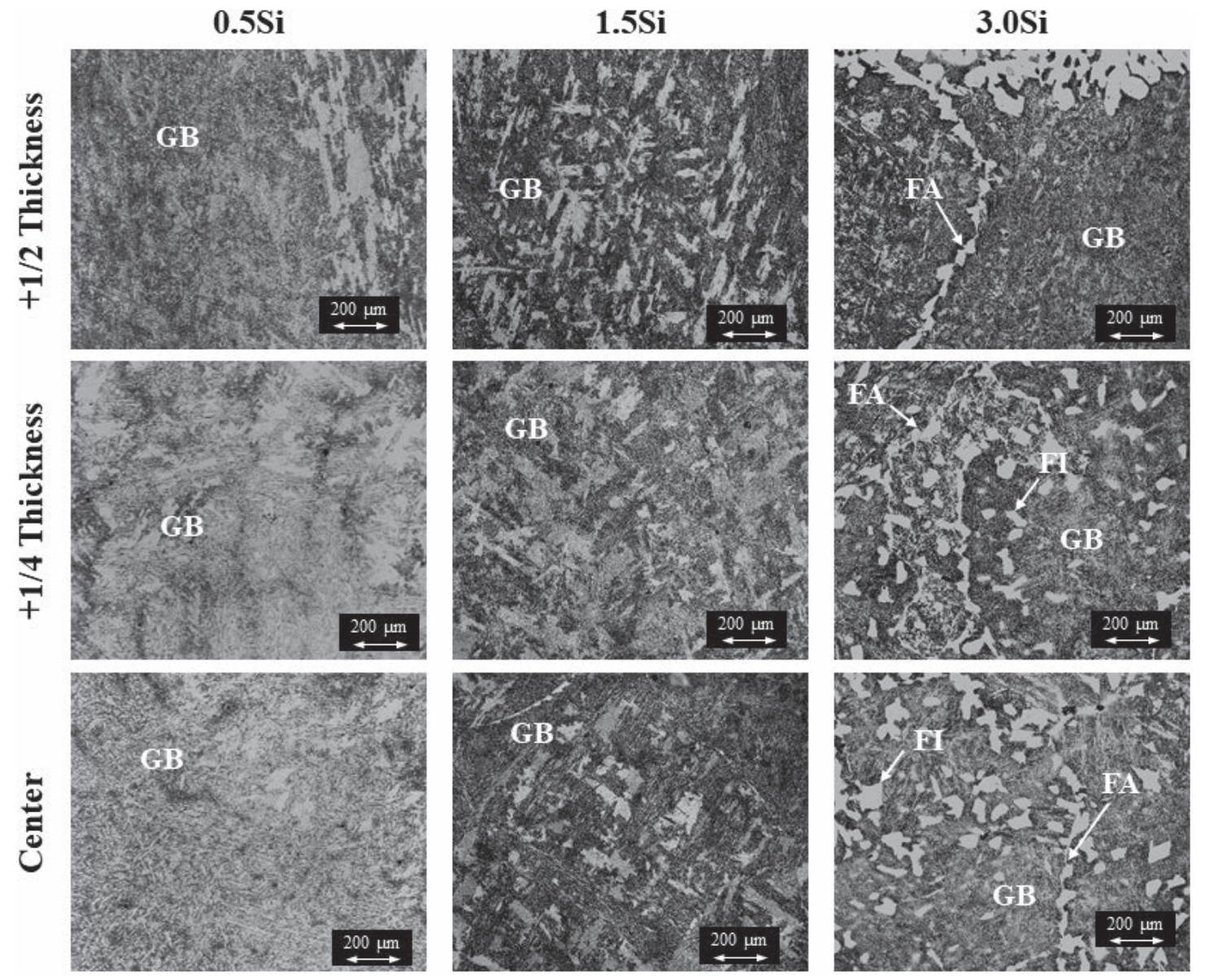

Fig. 3. LOM images of microstructures. 

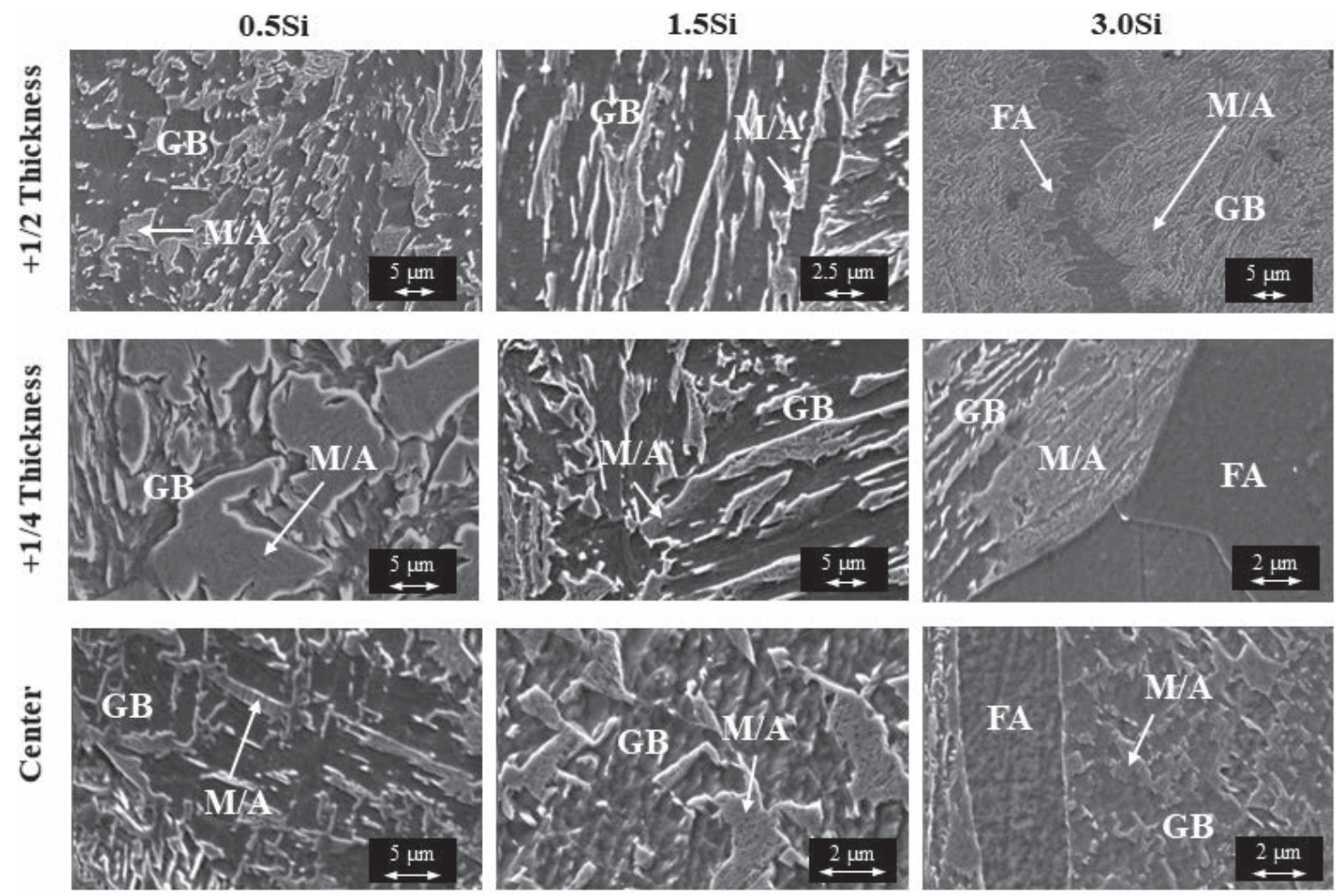

Fig. 4. SEM images and major constituents in microstructure.

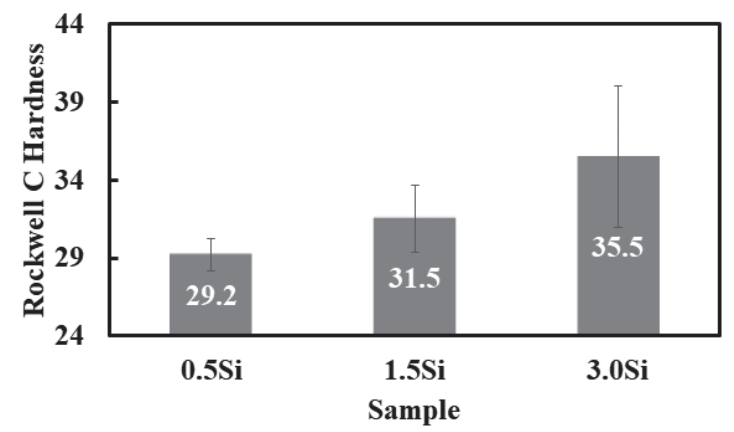

Fig. 5. Hardness Results.

- $\mathrm{FA}=$ ferrite allotriomorphs (ferrite precipitated at prior austenite grain boundaries)

- $\mathrm{FI}=$ ferrite idiomorphs (ferrite contained inside the prior austenite grain)

- $\mathrm{M} / \mathrm{A}=$ martensite-austenite

Rockwell C method was used to determine hardness of lab cast ingots. The average results are shown in Fig. 5, with error bars representing the standard deviation.

Figure 6 shows a summary of tensile test results and Fig. 7 shows examples of obtained engineering stress/strain curves. Max stress was used instead of UTS because the drop in the engineering stress/strain curve characteristic of necking was not observed.

Figure 8 shows SEM images of the tensile specimen fracture surfaces and Fig. 9 shows LOM images of the microstructure normal to the fracture surface.

Figure 10 shows the temperature profiles obtained through QuikCAST simulation at the center of a continuously cast slab in comparison with a lab cast air cooled ingot as the ones used in this work.

The results of thermodynamic/kinetic simulations of ferrite thickness with temperature cooling from $1200^{\circ} \mathrm{C}$ to $\mathrm{A}_{1}$

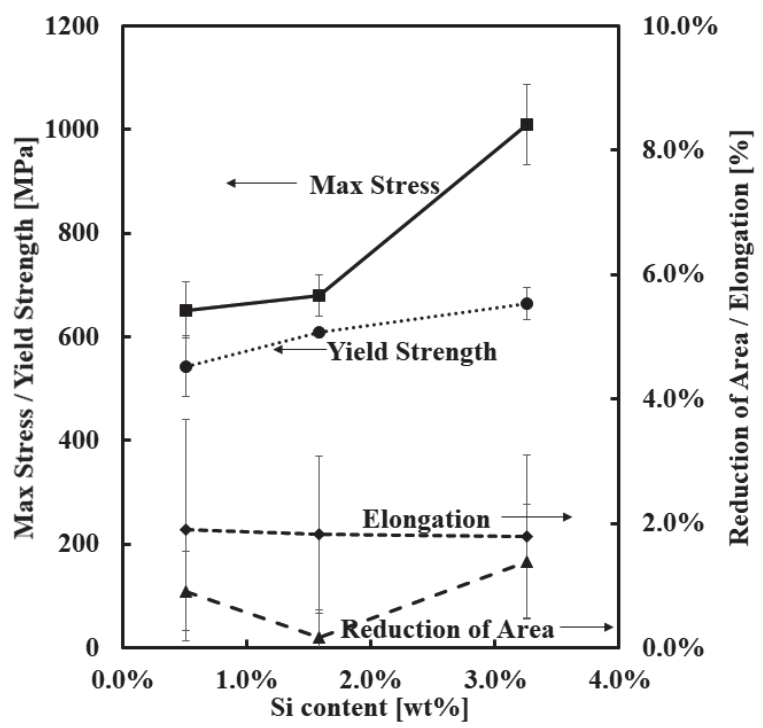

Fig. 6. Summary of tensile testing results.

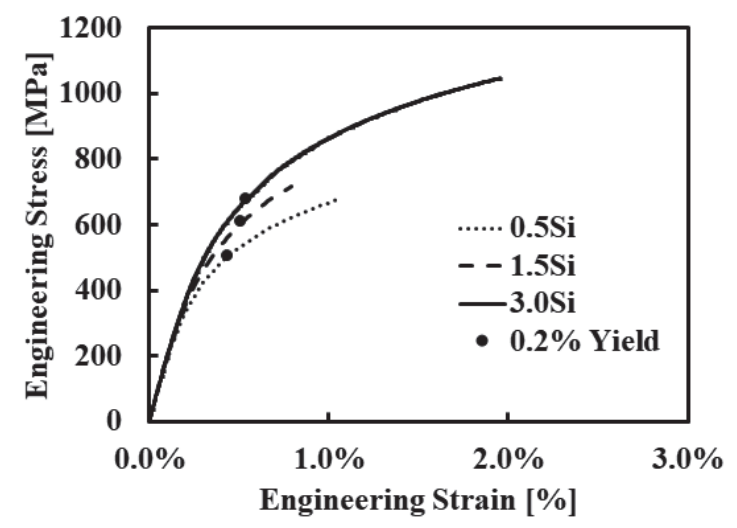

Fig. 7. Examples of obtained engineering stress vs. strain curves for all steels. 


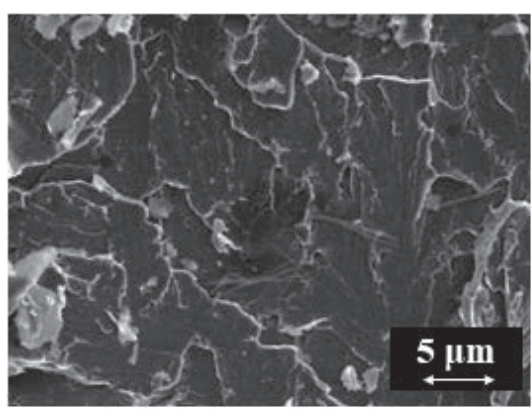

$0.5 \mathrm{Si}$

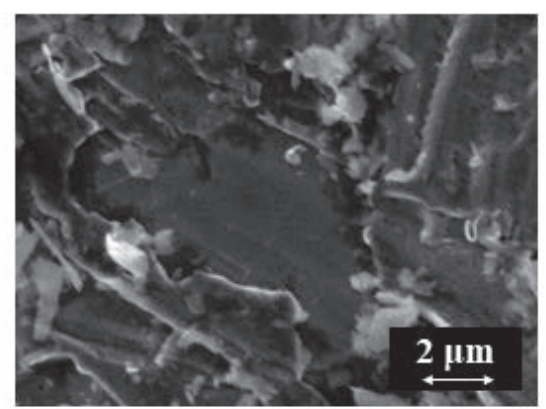

$1.5 \mathrm{Si}$

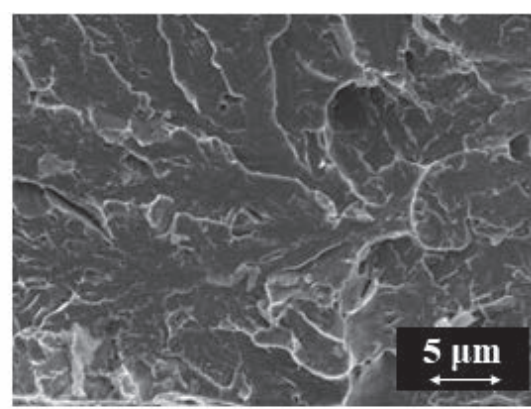

3.0 $\mathrm{Si}$

Fig. 8. SEM images of tensile specimen fracture surfaces.

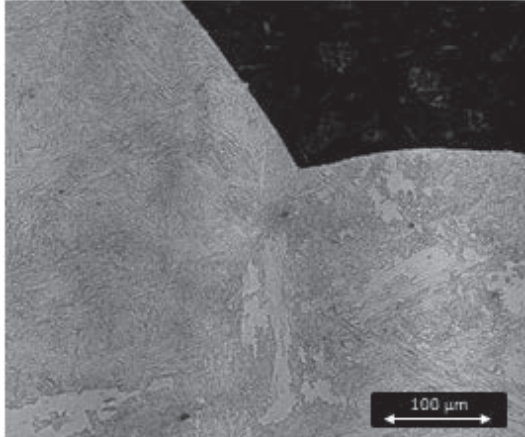

$0.5 \mathrm{Si}$

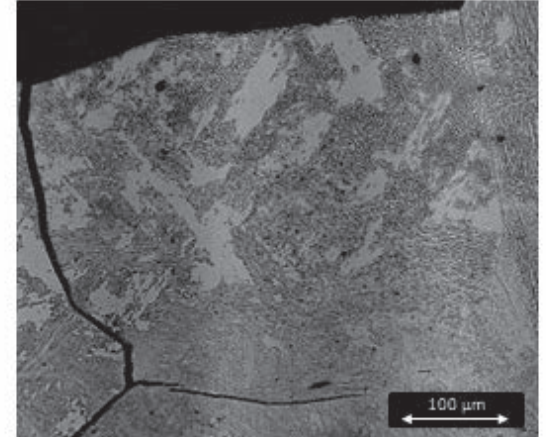

$1.5 \mathrm{Si}$

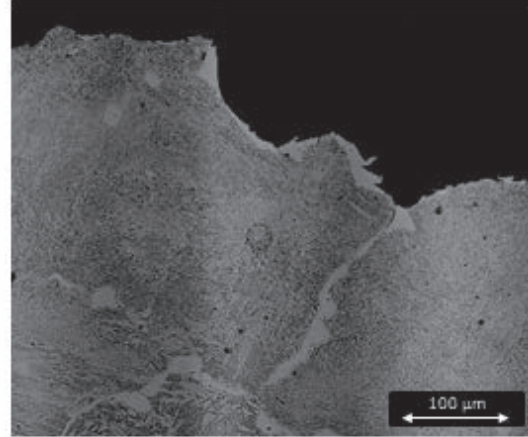

$3.0 \mathrm{Si}$

Fig. 9. LOM images of the cross section of tensile specimens normal to the fracture surface.

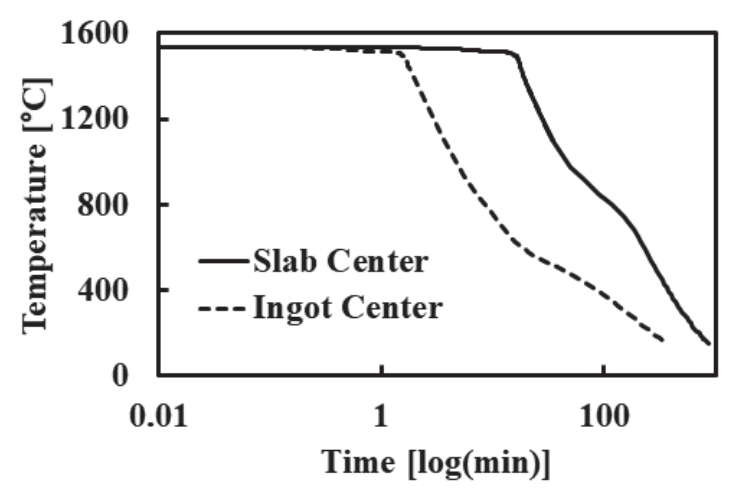

Fig. 10. Comparison between slab and ingot cooling from solidification using QuikCAST.

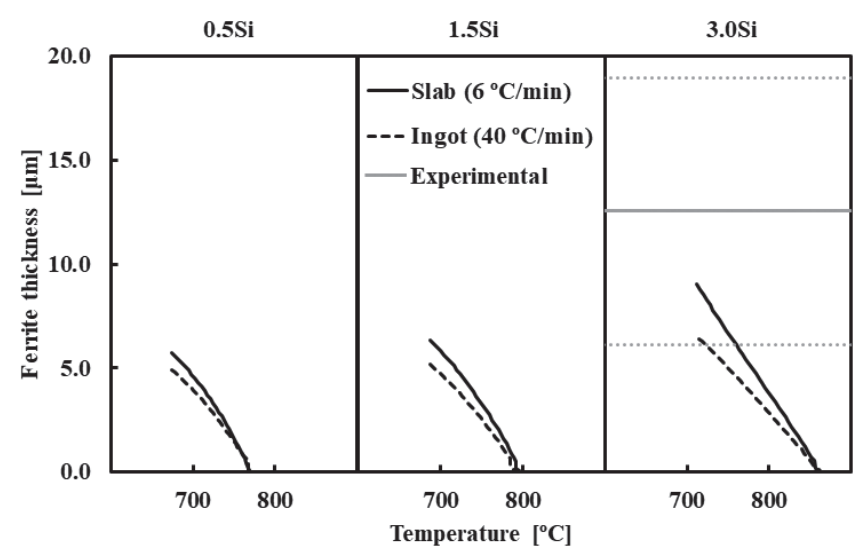

Fig. 11. DICTRA calculation of ferrite thickness with temperature upon cooling from $1200^{\circ} \mathrm{C}$ to $\mathrm{A}_{1}$ and experimental result of 3.0Si (grey dotted line bars represent standard deviation). as well as experimental measurement at the center of $3.0 \mathrm{Si}$ steel are shown in Fig. 11 for the three Si levels.

\section{Discussion}

The information in Figs. 3 and 4 showed that the microstructure changed with thickness only for 3.0Si steel, which are higher in $\mathrm{Si}$ content. The microstructures of $0.5 \mathrm{Si}$ and $1.5 \mathrm{Si}$ were very similar with granular bainite being the major constituent from surface to center thickness. 3.0Si presented pro-eutectoid ferrite decorating prior austenite grain boundaries (ferrite allotriomorphs) and granular bainite inside the grains. As the center of the ingot is approached, ferrite idiomorphs were also observed inside the prior austenite grains. Hardness, yield and max strength increased with silicon content, but no change in ductility could be observed since all fractures presented brittle behavior.

As it can be seen in these steels, granular bainite was the main microstructure constituent. A characteristic feature of granular bainite noted in the literature is the lack of carbides in the microstructure. Instead, the carbon that is partitioned from the bainitic ferrite stabilizes the residual austenite, so that the final microstructure should contain both retained austenite and some high-carbon martensite in addition to the bainitic ferrite. ${ }^{10)}$ From Fig. 4 it's possible to see that SEM image of granular bainite is composed of the elongated bainitic ferrite (dark gray) and the martensite-austenite constituents (M/A islands, light gray). ${ }^{26)}$

Higher silicon content led to more ferrite allotriomorphs, which can be explained in part by its role as a ferrite stabilizer. Figure 11 shows the results of thermodynamic/kinetic 
simulations of ferrite growth. Cooling rates corresponding to the calculated slab and ingot conditions from Fig. 10 were used in the simulation. Ferrite thickness increased with silicon content for both cooling rates. There was little difference in predicted thickness between $0.5 \mathrm{Si}$ and $1.5 \mathrm{Si}(4.9$ and $5.2 \mu \mathrm{m}$ at ingot cooling rate), compared to $6.4 \mu \mathrm{m}$ for 3.0Si. It's important to note that the model predicted ferrite growth for both $0.5 \mathrm{Si}$ and $1.5 \mathrm{Si}$ while none was observed in the experimental data and the thickness predicted by the model was lower than what was observed in the actual 3.0Si sample. The simulation ended at the $A_{1}$ temperature and the model did not account for eutectoid transformation products such as pearlite or bainite. Manganese and silicon decrease bainite start temperature. ${ }^{27-30)}$ Therefore, at lower silicon contents the ferrite may not have had sufficient time to grow before the bainitic transformation started. With 3 $\mathrm{wt} \% \mathrm{Si}$, some ferrite could grow at high temperatures before the bainitic transformation started.

The thickness of ferrite allotriomorphs was measured for 3.0Si through image processing. Ten measurements along ferrite allotriomorphs at the center of the ingot averaged to $12.5 \mu \mathrm{m}$. The calculated ferrite thickness for a $0.2 \% \mathrm{C}-3.0 \% \mathrm{Mn}-3.0 \% \mathrm{Si}$ steel is $6.4 \mu \mathrm{m}$, roughly half the measured in the center of the 3.0Si ingot (Fig. 11). However, the cooling profile was oversimplified, and the model did not account for transformations to pearlite or bainite during cooling. The measurement of ferrite thickness using LOM images was also subject to a large spread of data (which can be seen by the large standard deviation). The DICTRA calculation predicted some ferrite allotriomorphs for $0.5 \mathrm{Si}(4.9 \mu \mathrm{m})$ and $1.5 \mathrm{Si}(5.2 \mu \mathrm{m})$, but none was observed. This was again attributed to the absence of bainite or pearlite formation, i.e. in the actual ingots the other constituents formed before ferrite could grow to measurable thickness. This was due in large part to the effect of $\mathrm{Si}$ on the Ae3 temperature $-862^{\circ} \mathrm{C}$ for $3.0 \mathrm{Si}, 796^{\circ} \mathrm{C}$ for $1.5 \mathrm{Si}$, and $770^{\circ} \mathrm{C}$ for $0.5 \mathrm{wt} \% \mathrm{Si}$. This effect resulted in earlier ferrite precipitation at austenitic grain boundaries and more ferrite growth at higher temperatures. The observation of more ferrite formed with increasing $\mathrm{Si}$ was consistent with the work provided by Tsukatani et al. ${ }^{31)}$ where the authors studied continuous cooling transformation (CCT) curves for alloys with varying $\mathrm{Si}$. Slower cooling rate led to thicker ferrite, which is expected, since there was more time at higher temperatures for the transformation to occur.

The changes in microstructure due to $\mathrm{Si}$ also led to changes in mechanical behavior. It can be seen from Fig. 5 that hardness increased with silicon. This behavior is consistent to what is found in the literature. ${ }^{32,33)}$ Along with hardness, a slight increase in yield strength was observed with increasing silicon (Fig. 6). The example stress/strain curves in Fig. 7 also showed more work hardening occurred at 3.0Si. The measured percent elongation in Fig. 6 is larger than strain at fracture shown in Fig. 7 and this can be attributed to the variability of post fracture gauge measurement post fracture using a caliper. Nonetheless, both elongation and reduction of area were very low for all steels and fracture occurred before necking. The difference in behavior could be attributed to the presence of ferrite allotriomorphs. When ferrite is present, additional deformation can occur prior to fracture. Other studies have also shown wrought microstructures containing ferrite allotriomorphs + granular bainite possess higher max stress and strain at fracture than fully granular bainitic ones. ${ }^{26)}$

The fracture mechanism of these steels during the tensile test was also dependent on silicon content. All samples presented smooth fracture surface with no dimples (Fig. 8 ), a characteristic of brittle fracture. Cracks in 3.0Si followed ferrite allotriomorphs while no preferential path was identifiable in the fully bainitic $0.5 \mathrm{Si}$ and $1.5 \mathrm{Si}$ (Fig. 9). Crack initiation in ferrite was observed by $\mathrm{Xu}$ et al. ${ }^{26}$ ) for microstructures containing allotriomorphic ferrite and granular bainite. Kim et al. ${ }^{34,35)}$ observed the same kind of behavior for dual-phase (ferrite/martensite) steels with premature failure when ferrite allotriomorphs were present and Kunio et $a .^{36)}$ observed crack initiation in martensite, but propagation through ferrite in brittle fractures of carbon steels. In the case of fully bainitic structure, the cracking mechanism is well defined by $\mathrm{Xu}$ et al. $^{26)}$ with microcracks initiating at the interface between $\mathrm{M} / \mathrm{A}$ and bainitic ferrite, as strain progresses these microcracks connect and develop into the large cleavage cracks by cutting the M/A islands.

It is important to note that there will be differences in the expected microstructure for slabs. From Fig. 10 it's possible to see that there was a considerable difference in the predicted cooling rate of a lab cast ingot and a continuously cast slab. The ingots studied here would therefore be expected to have more constituents such as bainite in the microstructure. However, the observations and trends in the effect of silicon on microstructure and mechanical properties from this study should still be valid for industrial scale slabs and given the fracture behavior of the ingots studied in this work, the cooling conditions of slabs should take on greater importance as 3rd Generation AHSS move into wider production.

\section{Conclusions}

Three lab cast ingots with chemical compositions representing 3rd generation AHSS (with increasing Si content) were characterized by their microstructure and room temperature mechanical properties. Even though the effect of silicon on ductility could not be explained by room temperature tensile test, its effect on microstructure development and crack propagation were assessed in this work.

- There is great similarity between $0.5 \mathrm{Si}$ and $1.5 \mathrm{Si}$ bainitic microstructures; $3.0 \mathrm{Si}$ presented ferrite allotriomorphs along coarse prior austenite grain boundaries and granular bainite in the core of those prior austenite grains.

- Hardness and strength of steels increased with $\mathrm{Si}$ content mainly due to solution hardening.

- All ingots exhibited brittle fracture with no major differences in ductility, but crack propagation follows ferrite allotriomorphs when present.

- Silicon increases ferrite growth rate especially at levels $>1.5 \mathrm{wt} \%$.

\section{Acknowledgements}

The authors acknowledge use of the Materials Characterization Facility at Carnegie Mellon University supported by grant MCF-677785. We are also grateful for support of this work by the industrial members of the Center for Iron and 
Steelmaking Research.

\section{REFERENCES}

1) H. Aydin, E. Essadiqi, I. H. Jung and S. Yue: Mater. Sci. Eng. A, 564 (2013), 501.

2) M. C. Theyssier: Welding and Joining of Advanced High Strength Steels, Elsevier, Amsterdam, (2015), 29.

3) J. G. Speer, D. K. Matlock, L. Wang and D. V. Edmonds: Comprehensive Materials Processing, Elsevier, Amsterdam, (2014), 217.

4) R. M. Wu, L. Wang and X. J. Jin: Phys. Procedia, 50 (2013), 8.

5) A. Grajcar, R. Kuziak and W. Zalecki: Arch. Civ. Mech. Eng., 12 (2012), 334.

6) M. Bhargava, A. Tewari and S. K. Mishra: Mater. Des., 85 (2015), 149.

7) P. J. Gibbs: Ph.D. thesis, Colorado School of Mines, (2013), http:// hdl.handle.net/11124/78752, (accessed 2018-08-22).

8) P. D. Deeley, K. J. A. Kundig and H. R. Spendelow: Ferroalloys and Alloying Additives Handbook, Metallurgical Alloy, Newfield, (1981), 19, 46, 73

9) G. Krauss: Steels: Processing, Strcture and Performance, ASM International, Materials Park, (2005), 91, 161, 169, 337.

10) H. K. D. H. Bhadeshia and S. R. Honeycombe: Steels: Microstructure and Properties, 3rd ed., Butterworth-Heinemann, Oxford, (2006), $129,167$.

11) D. K. Matlock, J. G. Speer, E. De Moor and P. J. Gibbs: Jestech, 15 (2012), 1.

12) A. Grajcar, D. Woźniak and A. Kozłowska: Arch. Metall. Mater., 61 (2016), 811.

13) A. F. Ferreira, E. G. de Melo and L. de-Olivé Ferreira: Steel Res. Int., 86 (2015), 58.

14) Y. Meng and B. G. Thomas: Metall. Mater. Trans. B, 34 (2006), 685.

15) F. R. Camisani-Calzolari, I. K. Craig and P. C. Pistorius: Proc. IFAC Workshop on New Technologies for Automation of Metallurgical Industry, Elsevier, Amsterdam, (2003), 113.

16) E. Takeuchi and J. K. Brimacombe: Metall. Trans. B, 16 (1985), 605.

17) I. V. Samarasekera and J. K. Brimacombe: Metall. Trans. B, 13
(1982), 105 .

18) W. F. Savage, E. F. Nippes and E. S. Szekeres: Weld. Res. Suppl., (1976), 276.

19) J. A. Dantzig and M. Rappaz: Solidification, EPFL Press, Lausanne, (2009), 87.

20) D. M. Stefanescu: Science and Engineering of Casting Solidification, Springer, New York, (2009), 435.

21) Z. Zhang and R. A. Farrar: An Atlas of Continuous Cooling Transformation (CCT) Diagrams Applicable to Low Carbon Low Alloy Weld Metals, The Institue of Materials, London, (1995), 1.

22) J. Sengupta, B. G. Thomas and M. A. Wells: Metall. Mater. Trans. A, 36 (2005), 187.

23) S. Louhenkilpi, E. Laitinen and R. Nieminen: Metall. Trans. B, 24 (1993), 685.

24) J. O. Andersson, T. Helander, L. Höglund, P. Shi and B. Sundman: Calphad, 26 (2002), 273.

25) G. F. Vander Voort: Metallography: Principles and Practice, ASM International, Materials Park, (1999), 212.

26) P. Xu, B. Bai, F. Yin, H. Fang and K. Nagai: Mater. Sci. Eng. A, 385 (2004), 65.

27) L. Leach: Ph.D. thesis, KTH Royal Institute of Technology, (2018), http://www.diva-portal.org/smash/get/diva2:1205497/FULLTEXT01. pdf, (accessed 2018-08-22).

28) N. Usui, K. Sugimoto, E. Nishida, M. Kobayashi and S. Hashimoto: CAMP-ISIJ, 3 (1990), 2013 (in Japanese).

29 K. Sugimoto, J. Sakaguchi, T. Iida and T. Kashima: ISIJ Int., 40 (2000), 920.

30) K. Sugimoto, K. Nakano, S. Song and T. Kashima: ISIJ Int., 42 (2002), 450 .

31) I. Tsukatani, S. Hashimoto and T. Inoue: ISIJ Int., 31 (1991), 992.

32) G. E. Totten: Steel Heat Treatment: Metallurgy and Technologies, CRC Press, Boca Raton, (2007), 191.

33) C. T. Schade, T. Murphy, A. Lawley and R. Doherty: Int. J. Powder Metall., 48 (2012), 41.

34) N. J. Kim and G. Thomas: Metall. Trans. A, 12 (1981), 483.

35) N. J. Kim and G. Thomas: Scr. Metall., 18 (1984), 817.

36) T. Kunio, K. Yamada and H. Suzuki: Eng. Fract. Mech., 7 (1975), 411. 